\title{
RP-HPLC Method Development and Validation for Quantitative Analysis of Metformin and Gliclazide in Pharmaceutical Formulations
}

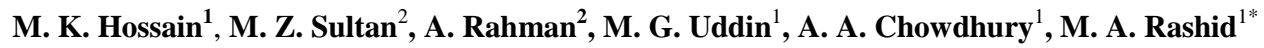 \\ ${ }^{1}$ Department of Pharmaceutical Chemistry, Faculty of Pharmacy, University of Dhaka, Dhaka-1000, \\ Bangladesh \\ ${ }^{2}$ Centre for Advanced Research in Sciences (CARS), University of Dhaka, Dhaka-1000, Bangladesh
}

Received 30 July 2013, accepted in final revised form 26 October 2013

\begin{abstract}
A rapid and sensitive isocratic reversed phase high performance liquid chromatographic method has been developed for quantitative analysis of metformin hydrochloride and gliclazide in bulk as well as pharmaceutical dosage forms. The method was validated according to FDA, ICH and USP guidelines with respect to accuracy, precision, specificity and linearity. For metformin, the method was developed by using the mobile phase comprising of sodium dihydrogen phosphate solution $\left(\mathrm{NaH}_{2} \mathrm{PO}_{4}\right)(\mathrm{pH} 3.0)$ and acetonitrile $(90: 10, \mathrm{v} / \mathrm{v})$ at a flow rate of $0.5 \mathrm{~mL} / \mathrm{min}$ over $\mathrm{C}_{18}$ bonded silica column $(3.9 \times 300 \mathrm{~mm}, 5$ $\mu \mathrm{m})$ at ambient temperature. On the other hand, the same mobile phase was used in the ratio of $20: 80(\mathrm{v} / \mathrm{v})$ at a flow rate of $0.6 \mathrm{~mL} / \mathrm{min}$ for gliclazide. The recovery was found to be more than $97 \%$ for metformin and $102 \%$ for gliclazide that demonstrated the accuracy of the protocol. Intraday and interday precisions of the new method were less than the maximum allowable limit $(\%$ RSD $\leq 2.0)$ specified by the USP, ICH and FDA. The method revealed linear response with correlation coefficient value of 0.999 in both cases.
\end{abstract}

Keywords: Metformin; Gliclazide; RP-HPLC; Method development.

๑) 2014 JSR Publications. ISSN: 2070-0237 (Print); 2070-0245 (Online). All rights reserved.

doi: http://dx.doi.org/10.3329/jsr.v6i1.15963 J. Sci. Res. 6 (1), 161-168 (2014)

\section{Introduction}

Diabetes Mellitus (DM) is now recognized as a global health challenge for the $21 \mathrm{st}$ century. The number of people with diabetes is increasing due to population growth, aging, urbanization, and increasing prevalence of obesity and physical inactivity [1]. Like all other developed and developing countries, prevalence and incidence of type 2 DM is also increasing in Bangladesh. In 2010, the International Diabetes Federation (IDF) estimated that 5.7 million (6.1\%) and 6.7 million (7.1\%) of people living in Bangladesh are suffering from diabetes and impaired glucose tolerance (IGT), respectively. By 2030,

\footnotetext{
*Corresponding author: rashidma@univdhaka.edu
} 
that number of diabetic population is suspected to rise to 11.1 million. So anti-diabetic drugs have got huge market demand in Bangladesh. Compared to insulin, oral hypoglycemic agents are becoming popular day by day due to affordability, ease of handling and administration.

Pharmaceutical manufacturers collect raw materials from different sources and accordingly the quality of raw materials may differ from company to company. But the quality of the finished products is primarily dependent upon the quality of APIs.

Metformin and gliclazide are frequently prescribed oral hypoglycemic agents which have several advantages over other conventional agents. Metformin is a drug in the biguanide class that also increases insulin sensitivity. It also reduces glucose production by the liver. It is the most commonly-used agent for type II diabetes in children and teenagers and is suitable for women with gestational diabetes. Gliclazide is an oral hypoglycemic (anti-diabetic) drug and is chemically classified as a sulfonylurea derivative.

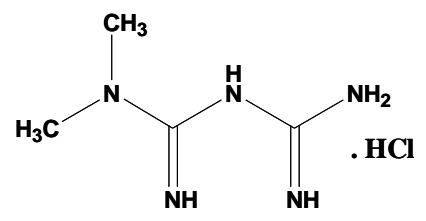

Metformin $\mathrm{HCl}$

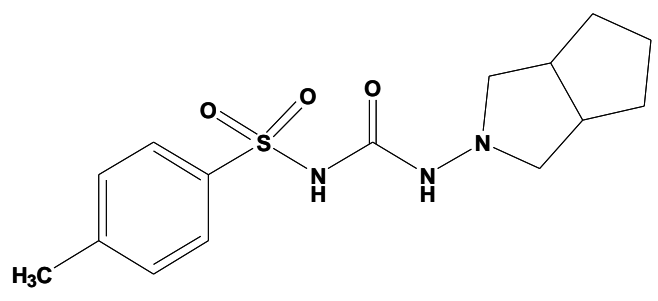

Gliclazide

Many methods have been reported in the literature for the estimation of metformin hydrochloride and gliclazide [2-6]. However none of these methods are free from limitations. Most of the methods used gradient solvent systems which is complex and expensive. Therefore, development of a simple HPLC method for the estimation of metformin hydrochloride and gliclazide is highly desirable. Recently, we reported the development and validation of a simple and sensitive RP-HPLC method for the estimation of several drugs in pharmaceutical dosage forms formulated in Bangladesh [7-9]. As a part of our continuous studies of analytical method development, we developed a simple and less expensive reversed-phase HPLC method using isocratic solvent system with high accuracy and sensitivity for the estimation of drug sample in pharmaceutical raw materials as well as finished products.

\section{Experimental}

\subsection{Raw materials and chemicals}

Standard samples of metformin and gliclazide with potency of $99.65 \%$ and $99.29 \%$, respectively were obtained as gift samples from Drug International Ltd., Dhaka, 
Bangladesh. Raw materials of metformin and gliclazide were also obtained as gifts from ACI Pharmaceuticals Ltd., Dhaka, Bangladesh. Finished products of these drugs were purchased from local market. Acetonitrile (HPLC grade), sodium dihydrogen phosphate and orthophosphoric acid were purchased from Active Fine Chemicals Ltd., Dhaka, Bangladesh.

\subsection{Instruments}

High Performance Liquid Chromatographic system (Shimadzu-UFLC Prominence), equipped with an auto sampler (Model- SIL 20AC HT) and UV-Visible detector (ModelSPD 20A) were used for the analysis. The data was recorded using LC-solutions software. Analytical reversed phase C-18 column $[3.9$ x $300 \mathrm{~mm}, 5 \mu \mathrm{m}$ particle size, $\mu$ BondapakTM, Waters, USA] was used for the HPLC instrument.

\subsection{Preparation of mobile phase}

To prepare sodium dihydrogen phosphate solution of $\mathrm{pH} 3.0$, sodium dihydrogen phosphate $(195.5 \mathrm{mg}$ ) was taken in each of the two $1000 \mathrm{~mL}$ volumetric flasks. Then 500 $\mathrm{mL}$ of distilled water was added into the flask, dissolved the salt and finally distilled water was added up to the mark. Then $\mathrm{pH}$ was adjusted at 3.0 by adding dilute phosphoric acid, sonicated for 10 minutes and then filtered through a $0.22 \mu \mathrm{m}$ millipore filter. HPLC grade actonitrile was also filtered and degassed before pumping into the system.

\subsection{Preparation of standard solutions}

$12.845 \mathrm{mg}$ metformin hydrochloride (equivalent to $12.8 \mathrm{mg}$ of standard metformin hydrochloride) was dissolved in water and made up to $100 \mathrm{~mL}$ in a volumetric flask (concentration $128 \mu \mathrm{g} / \mathrm{mL}$ ). Similarly, $12.89 \mathrm{mg}$ gliclazide powder (equivalent to $12.8 \mathrm{mg}$ of standard gliclazide) was dissolved in methanol and made up to $100 \mathrm{~mL}$ in a volumetric flask (concentration $128 \mu \mathrm{g} / \mathrm{mL}$ ). Then by calculation and serial dilution procedure solutions of various concentrations such as $8,16,32,64,128 \mu \mathrm{g} / \mathrm{mL}$ were prepared for both metformin and gliclazide.

\subsection{Preparation of test samples}

Ten tablets in each of the samples (Sample-1, Sample-2 and Sample-3) of each drug were weighed, ground into fine powder with mortar and pestle and the average weight was taken. First of all, the powder equivalent to $10 \mathrm{mg}$ of metformin hydrochloride was dissolved in enough water to make $100 \mathrm{~mL}$ to get $100 \mu \mathrm{g} / \mathrm{mL}$. An aliquot $(5 \mathrm{~mL})$ of this solution was taken in a $10 \mathrm{~mL}$ volumetric flask and $5 \mathrm{~mL}$ of water was added into it (concentration $50 \mu \mathrm{g} / \mathrm{mL}$ ). Similarly, powder equivalent to $5 \mathrm{mg}$ gliclazide was dissolved in methanol and the final volume was adjusted to $100 \mathrm{~mL}$ resulting in a concentration of 
$50 \mu \mathrm{g} / \mathrm{mL}$. Then $5 \mathrm{~mL}$ of this solution was diluted with $5 \mathrm{~mL}$ of methanol (concentration $25 \mu \mathrm{g} / \mathrm{mL}$ ). Test samples of similar concentrations were also prepared for active raw materials.

\subsection{Chromatographic conditions}

For metformin, the mobile phase contained sodium dihydrogen phosphate $\left(\mathrm{NaH}_{2} \mathrm{PO}_{4}\right)$ solution ( $\mathrm{pH} 3.0)$ and acetonitrile in the ratio of 90:10 $(\mathrm{v} / \mathrm{v})$ at a flow rate of $0.5 \mathrm{~mL} / \mathrm{min}$. The injection volume was $20 \mu \mathrm{L}$ for both standard and samples. The $\mathrm{pH}$ of the mobile phase was maintained at 3.0 and run time was set for $7 \mathrm{~min}$. On the other hand for gliclazide, the same mobile phase was used in the ratio of 20:80 $(v / v)$ at a flow rate of 0.6 $\mathrm{mL} / \mathrm{min}$. The injection volume was $20 \mu \mathrm{L}$ for standard and samples.

Before analysis, every standard and sample were filtered through $0.45 \mu \mathrm{m}$ filter tips. The mobile phase was also filtered, sonicated and degassed before use. The column eluate was monitored with a UV detector at $254 \mathrm{~nm}$ for metformin and $230 \mathrm{~nm}$ for gliclazide. All analyses were done at ambient temperature under isocratic conditions.

\subsection{Method Validation}

\subsubsection{Linearity}

Five different samples were prepared having concentrations of 8, 16, 32, 64 and 128 $\mu \mathrm{g} / \mathrm{mL}$ for standard solution by dissolving in water (in case of metformin) and in methanol (in case of gliclazide). Then $20 \mu \mathrm{L}$ from each solution was injected using autosampler and the analyses were monitored at $254 \mathrm{~nm}$ (in case of metformin) and at $230 \mathrm{~nm}$ (in case of gliclazide) and repeated three times. The average peak areas were plotted against respective concentration. The linearity of the proposed method was evaluated by using calibration curves to calculate coefficient of correlation and intercept values.

\subsubsection{Accuracy}

The accuracy of the method is the nearness of the result obtained to the true value. The accuracy is expressed by calculating the percent recovery $(R \%)$ of analyte recovered by the assay of spiked samples. To evaluate the accuracy of the proposed method, successive analysis $(n=3)$ for three different concentrations $(40 \mu \mathrm{g} / \mathrm{mL}, 50 \mu \mathrm{g} / \mathrm{mL}$ and $60 \mu \mathrm{g} / \mathrm{mL})$ of standard metformin and gliclazide solutions were carried out by using the proposed method.

\subsubsection{Precision/reproducibility}

Precision of the assay was assessed with respect to both repeatability and reproducibility. The precision of an analytical method is the degree of agreement among individual test 
results where the method is applied repeatedly to multiple samplings. It was checked by intra- and inter-day repeatability of responses after replicate injections and expressed as RSD \% amongst responses using the formula [RSD $(\%)=($ Standard deviation/Mean $) \mathrm{x}$ $100 \%$ ]. In the current method development and validation protocol, precision was determined by using single concentration of $64 \mu \mathrm{g} / \mathrm{mL}$ for both standard metformin and gliclazide solutions.

\subsubsection{Sample analysis}

To quantify the active drugs in finished pharmaceutical formulation, successive analysis $(n=3)$ of the samples of metformin and gliclazide were analyzed by the proposed method and the contents were determined by using the calibration curve and the formula, $y=m x+c$.

\section{Results and Discussions}

HPLC is one of the most powerful and accurate analytical technique used for qualitative and quantitative determinations of bulk and finished pharmaceutical preparations. A reversed phase HPLC method has been developed and validated as per the ICH, USP and FDA guidelines for determination of gliclazide and metformin in pharmaceutical raw materials and finished products by using the mobile phase comprising sodium dihydrogen phosphate and acetonitrile. In case of metformin, the ratio of sodium dihydrogen phosphate solution $(\mathrm{pH} \mathrm{3.0)}$ and acetonitrile was 90:10 $(v / v)$. The flow rate was kept at $0.5 \mathrm{~mL} / \mathrm{min}$ and $\mathrm{UV}$ detection was made at $254 \mathrm{~nm}$. The retention time obtained at $4.8 \pm 0.05 \mathrm{~min}$ (Fig. 1).

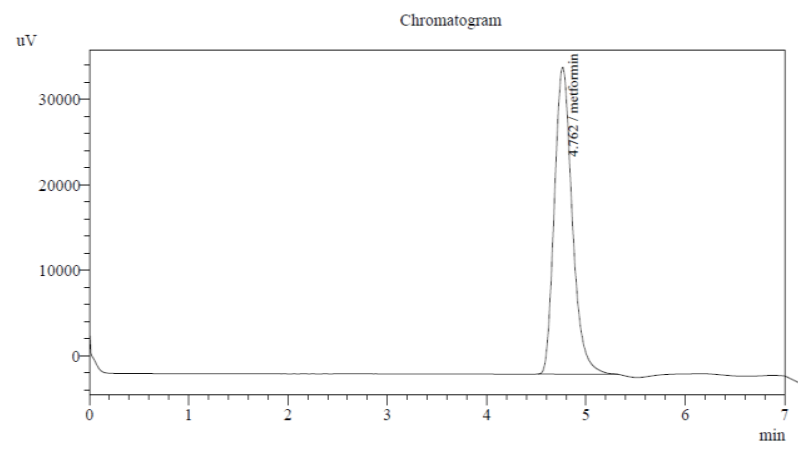

Fig. 1. Chromatograms of metformin.

On the other hand, in case of gliclazide, the same mobile phase was used in the ratio of 20:80 $(v / v)$ at ambient temperature. Here the flow rate was kept at $0.6 \mathrm{~mL} / \mathrm{min}$ with UV detection at $230 \mathrm{~nm}$. The retention time of gliclazide was obtained at $6.6 \pm 0.1 \mathrm{~min}$ (Fig. 2). The injection volume was kept at $20 \mu \mathrm{L}$ for all standards and samples in both the cases. 


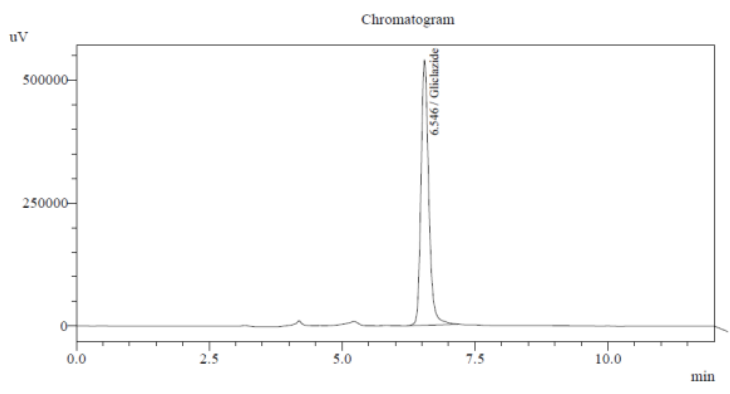

Fig. 2. Chromatograms of gliclazide.

When peak area (y) was plotted against concentration levels of $8 \mu \mathrm{g} / \mathrm{mL}, 16 \mu \mathrm{g} / \mathrm{mL}, 32$ $\mu \mathrm{g} / \mathrm{mL}, 64 \mu \mathrm{g} / \mathrm{mL}$ and $128 \mu \mathrm{g} / \mathrm{mL}$, a good correlation coefficient was obtained. For the equation of calibration curve, correlation coefficient $\left(r^{2}\right)$ was obtained as 0.999 for both metformin and gliclazide which was within the acceptable guidelines and it showed a good linear relationship of the newly developed methods. The slope $(\mathrm{m})$ and intercept $(\mathrm{c})$ of the calibration curve were found to be 10393 and -28116 for metformin and 83758 and -4174 for gliclazide, respectively (Table 1, Fig. 3).

Table 1. Linearity of developed method of metformin and gliclazide.

\begin{tabular}{|c|c|c|c|c|c|c|c|c|}
\hline \multirow[t]{2}{*}{$\begin{array}{c}\text { Conc. } \\
(\mu \mathrm{g} / \mathrm{mL})\end{array}$} & \multirow{2}{*}{$\begin{array}{c}\text { Mean area }(y) \\
\text { Met }\end{array}$} & \multirow{2}{*}{$\begin{array}{l}(\mathrm{n}=3) \\
\mathrm{Glz}\end{array}$} & \multicolumn{2}{|c|}{ Slope $(m)$} & \multicolumn{2}{|c|}{ Intercept $(c)$} & \multicolumn{2}{|c|}{$\begin{array}{c}\text { Correlation } \\
\text { coefficient }\left(r^{2}\right)\end{array}$} \\
\hline & & & Met & Glz & Met & Glz & Met & Glz \\
\hline 8 & 72236 & 678458 & & & & & & \\
\hline 32 & 284673 & 2644367 & 10393 & 83758 & -28116 & -4174 & 0.9992 & 0.9999 \\
\hline 128 & 1310337 & 10742331 & & & & & & \\
\hline
\end{tabular}

(Met $=$ Metformin, Glz = Gliclazide) .

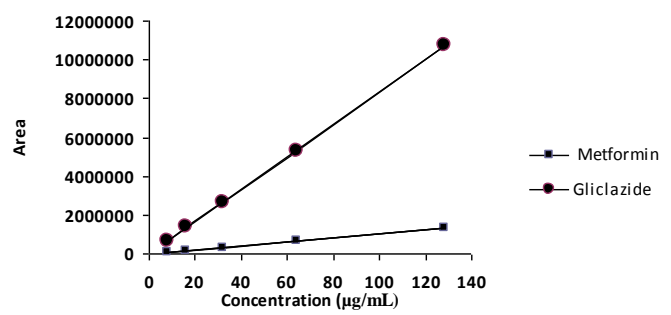

Fig. 3. Standard calibration curve for metformin and gliclazide.

The accuracy was evaluated at three different concentrations with spiked samples which were conducted in successive analysis $(n=3)$ using the proposed method and the value was expressed as percentage of recovery between the mean concentrations found 
and added concentration for both of these drugs. For metformin, the average percentage of recovery was found to be $98.95,98.60$ and 97.86 for $40 \mu \mathrm{g} / \mathrm{mL}, 50 \mu \mathrm{g} / \mathrm{mL}$ and $60 \mu \mathrm{g} / \mathrm{mL}$, respectively and for gliclazide, the average percentage of recovery was found to be 102.17, 102.32 and 102.02 for the same concentrations (Table 2).

All experimental results were within the acceptable range of precision and accuracy, which indicated that the developed methods are sensitive enough and accurate for determination of gliclazide and metformin.

Table 2. Accuracy of the developed method for assay of metformin and gliclazide.

\begin{tabular}{cccc}
\hline $\begin{array}{c}\text { Standard } \\
\text { metformin }+ \text { spike }(\mu \mathrm{g} / \mathrm{mL})\end{array}$ & $\begin{array}{c}\text { Total concentration } \\
\text { for analysis }(\mu \mathrm{g} / \mathrm{mL})\end{array}$ & $\begin{array}{c}\text { Recovered } \\
\text { mean }(n=3)\end{array}$ & \% recovery \\
\hline $10+30$ & 40 & 39.58 & 98.95 \\
$20+30$ & 50 & 49.30 & 98.60 \\
$30+30$ & 60 & 58.72 & 97.86 \\
Standard & & & \\
gliclazide + spike $(\mu \mathrm{g} / \mathrm{mL})$ & & & 102.17 \\
$10+30$ & 40 & 40.87 & 102.32 \\
$20+30$ & 50 & 51.16 & 102.02 \\
\hline $30+30$ & 60 & 60.87 & \\
\hline
\end{tabular}

The precision of the proposed method was also checked by intra-day and inter-day repeatability of responses after replicate injections of standard solutions $(64 \mu \mathrm{g} / \mathrm{mL})$ for six times in a day for three days where the mean concentrations were found as 65.38 $\mu \mathrm{g} / \mathrm{mL}, 64.85 \mu \mathrm{g} / \mathrm{mL}$ and $65.24 \mu \mathrm{g} / \mathrm{mL}$ for each single day with associated \%RSDs of $0.05 \%, 0.66 \%$ and $0.15 \%$, respectively.

These methods were applied for quantitative analysis of metformin or gliclazide tablets formulated by local manufacturers. The quantity of active drug was determined for three marketed preparations (sample-1, sample-2 and sample-3) for each drug and the potency of metformin hydrochloride was found as $98.12 \%, 99.02 \%$, and $98.69 \%$, respectively, and for gliclazide as $104.81 \%, 102.70 \%, 100.89 \%$, respectively (Table 3).

Table 3. Determination of drugs content in the finished products of metformin and gliclazide.

\begin{tabular}{ccccccc}
\hline $\begin{array}{c}\text { Metformin } \\
\text { hydrochloride }\end{array}$ & $\begin{array}{c}\text { Injected } \\
\text { conc. } \\
(\mu \mathrm{g} / \mathrm{mL})\end{array}$ & $\begin{array}{c}\text { Average } \\
\text { peak area } \\
(y)\end{array}$ & Slope $(m)$ & Intercept $(\mathrm{c})$ & $\begin{array}{c}\text { Recovered } \\
{[x=(y-c) / m]}\end{array}$ & $\begin{array}{c}\text { \%Recovered } \\
{[=(\text { recovered conc./injected }} \\
\text { conc.) x100] }\end{array}$ \\
\hline Sample-1 & 50 & 481736 & 10393 & -28116 & 49.05725 & 98.12 \\
Sample-2 & 50 & 486429 & 10393 & -28116 & 49.50880 & 99.02 \\
sample-3 & 50 & 484736 & 10393 & -28116 & 49.34590 & 98.69 \\
Gliclazide & & & & & & \\
Sample-1 & 25 & 2190566 & 83758 & -4174 & 26.2033477 & 104.81 \\
Sample-2 & 25 & 2146316 & 83758 & -4174 & 25.6750399 & 102.70 \\
sample-3 & 25 & 2108435 & 83758 & -4174 & 25.2227727 & 100.89 \\
\hline
\end{tabular}




\section{Conclusion}

The activity of a drug depends on some absolute requirements such as quality, potency, etc. It is obvious that a little change in the formulation or variations in the manufacturing process or use of poor quality materials including APIs (Active Pharmaceutical Ingredients) and fake or expired drugs can influence the efficacy of the drug as well as may produce harmful effects to the patients. Therefore, quality and efficacy assessments and maintenance of proper dose schedule are strongly emphasized to ensure the effectiveness of the drug. To ensure the requisite quality, drug manufacturers are required to test their products during and after the manufacturing processes and at various intervals during the shelf life of the product. Hence, we planned to study and determine the potency and efficacy of most commonly used anti-diabetic agents like gliclazide and metformin, which are widely prescribed in Bangladesh. To attain this objective, a rapid and sensitive reversed phase high performance liquid chromatographic method has been developed and validated according to the FDA, ICH and USP guidelines with respect to accuracy, precision, specificity and linearity. The developed method was found to be simple, accurate, reproducible, efficient and less time consuming, and was applied successfully for the study of gliclazide and metformin in pharmaceutical raw materials and finished products. Therefore, this method could easily be used to analyze

\section{Acknowledgement}

The authors are thankful to ACI Pharmaceuticals Ltd. and Drug International Ltd., Bangladesh for the generous gift of metformin hydrochloride and gliclazide standard as well as raw materials for the research.

\section{References}

1. S. Wild, G. Rojlic, A. Green, R. Sicree, and H. King, Diabet. Care 27 (5), 1047 (2004).

2. British Pharmacopoeia, Vol. 1 (The Stationary Office, MHRA British Pharmacopoeial Commission Office, London, 2005).

3. R. Huupponen, K. P. Ojala, J. Rouru, and M. Koulu, J. Chromatogr. B. Biomed. Sci Appl. 583 (2), 270 (1992). http://dx.doi.org/10.1016/0378-4347(92)80564-7

4. M. Vasudevan, J. Ravi, S. Ravisankar, and B. Suresh. J. Pharm. Biomed. Anal. 25 (1), 77 (2001). http://dx.doi.org/10.1016/S0731-7085(00)00493-3

5. V. Porta, S. G. Schramm, E. K. Kano, E. E. Koono, Y. P. Armando, K. Fukuda, and C. H. R. Serra, J. Pharm. Biomed. Anal. 46 (1), 143 (2008). http://dx.doi.org/10.1016/j.jpba.2007.10.007

6. K. Fatema, M. Z. Rahman, T. Haque, M. A. K. Azad, and M. S. Reza, Dhaka Univ. J. Pharm. Sci. 9 (2), 83 (2010). doi: http://dx.doi.org/10.3329/dujps.v9i2.7884

7. M. Z. Sultan, G. Zia-Ul-Huda, M. A. Hossain, M. A. Mazid, and M. A. Ars, Pharm. 53 (1), 11 (2012).

8. M. Z. Sultan, A. Rahman, M. A. Hossain, and M. A. Rashid, J. Dhaka Int. Univ. 3 (1), 121 (2011).

9. M. Z. Sultan, M. A. Mazid, and M. A. Rashid, J. Sci. Res. 3 (2), 383 (2011). http://dx.doi.org/10.3329/jsr.v3i2.7024 